\title{
L'ÉDITION GÉNOMIQUE DES ANIMAUX DOMESTIQUES : QUELS ENJEUX ET QUEL AVENIR ?
}

\author{
GENOMIC EDITING OF DOMESTIC ANIMALS: WHAT ARE THE STAKES \\ AND FOR WHAT FUTURE?
}

Par Jean-Louis GUÉNET ${ }^{l}$

Mémoire accepté le 24 auril 2021

\section{RÉSUMÉ}

En utilisant les techniques modernes d'ingénierie de l'ADN, les généticiens sont aujourd'hui capables de modifier précisément la structure du génome des animaux domestiques et, pour qualifier ce genre de modifications, il est désormais convenu de parler "d'édition génique" ou "d'édition génomique". Dans la plupart des cas ces modifications se traduisent par des modifications plus ou moins importantes du phénotype : c'est pourquoi le sujet intéresse la profession vétérinaire et beaucoup d'autres professions du monde rural. Cependant, si cette nouvelle approche ouvre assurément des perspectives nouvelles et intéressantes, elle soulève aussi des controverses. Sur la base d'exemples publiés, cette revue présente un inventaire des moyens utilisables pour modifier la structure du génome des mammifères domestiques et discute l'intérêt d'une telle entreprise. La dernière partie est un plaidoyer pour inciter les législateurs, notamment européens, à reconsidérer les directives en vigueur, depuis plus de vingt ans, à la lumière de données récentes. Le statu quo actuel est devenu difficilement acceptable

Mots-clés : édition génomique, animaux domestiques.

\begin{abstract}
Using modern DNA engineering techniques, geneticists are now able to precisely alter the genomic structure of domestic animals and, in order to describe these kinds of changes, it has become common to speak of "gene or genomic editing". In most cases these genomic changes result in more or less significant changes in the phenotypes, which is why the subject is of interest to the veterinary community and many other professions in the rural world. However, while this new approach certainly opens up interesting perspectives, it is also controversial. Based on published examples, this review presents an inventory of how the genomic structure of domestic mammals can be modified and discusses the value of such a venture. The last part is a plea to urge legislators, especially European ones, to review in the light of recent data the orders and laws, which have been in force concerning genomic edition for now over twenty years. The current status quo has become difficult to accept. Key-Words: genome editing, domestic animals
\end{abstract}

(1 Chef de Service honoraire à l'Institut Pasteur, Membre émérite de l'Académie Vétérinaire de France. Courriel : j.lguenet@orange.fr 


\section{INTRODUCTION}

Le prix Nobel de chimie 2020 a été attribué à la française Emmanuelle Charpentier ${ }^{1}$ et à l'américaine Jennifer Doudna ,"for the development of a method for genome editing ${ }^{2 "}$, autrement dit pour le développement d'une méthode expérimentale qui permet d'induire, pratiquement à volonté, toute une variété de modifications structurales dans l'ADN génomique d'un organisme vivant. L'attribution de cette récompense était attendue par la communauté des biologistes en raison de la simplicité et de l'universalité de la méthodologie utilisée et, surtout, en raison de la richesse de ses applications potentielles dans un grand nombre d'espèces animales ou végétales (Tait-Burkard et al. 2018 ; Van Eenennaam, 2019 ; Menchaca et al. 2020). Ce prix Nobel fournit aussi une occasion de relancer une controverse et des spéculations de tous ordres à propos de la question de savoir jusqu'à quel point il est éthique, et par conséquent acceptable, de modifier la structure du génome des animaux domestiques. Nous aborderons quelques aspects de cette controverse qui concernent plus spécialement la profession vétérinaire après avoir rappelé brièvement ce que contient, en 2021, la "boite à outils" des généticiens s'intéressant aux mammifères domestiques et ce qu'il est possible de faire avec ${ }^{3}$.

\section{COMMENT MODIFIER LE GÉNOME DES ANIMAUX DOMESTIQUES ?}

\section{La transgénèse par addition in ovo d'ADN étrangers}

Au cours des années 1970, la composition des milieux de culture pour embryons précoces a fait l'objet d'améliorations substantielles qui ont rendu possibles le maintien et la manipulation in vitro de la plupart des embryons de mammifères, depuis le stade une cellule jusqu'au stade blastocyste. Profitant de cette "fenêtre d'accès" à l'embryon les chercheurs ont alors commencé à envisager la possibilité de modifier la structure du génome des animaux en utilisant une approche directe, mécanique, consistant à ajouter à l'aide d'une micropipette de verre effilée un fragment d'ADN cloné, directement dans l'un des deux pronuclei d'un embryon au stade une cellule (Figure 1). En utilisant cette approche, les généticiens espéraient que l'ADN exogène pourrait s'incorporer à l'ADN génomique de l'embryon manipulé et si, par construction, cet ADN exogène apportait avec lui les séquences nécessaires à son expression ${ }^{4}$. Ils pensaient ainsi que l'ADN exogène s'exprimerait comme n'importe quel autre gène de l'hôte. L'expérience aboutirait alors à la création d'un animal ayant acquis un gène supplémentaire, autrement que par le canal habituel de l'hérédité, un gène pouvant éventuel- lement provenir d'une autre espèce selon l'origine de l'ADN. Un très grand nombre de tels animaux "transgéniques" ont ainsi été créés à partir des années 1980 et nombreux sont les biologistes qui se souviennent encore aujourd'hui de l'énorme souris trangénique produite dans le laboratoire de Richard Palmiter (University of Washington) et qui fit la couverture de la revue Nature (vol 300 n$^{\circ}$ 5893) - Palmiter et al. 1982). Chez cette souris, le gène codant l'hormone de croissance du rat, placé sous le contrôle d'un promoteur fort et introduit par transgénèse, était exprimé de manière quasi constitutive ce qui rendait certaines souris beaucoup plus grosses que les souris témoins (jusqu'à $110 \mathrm{~g})$. Ces expériences apportaient pour la première fois la preuve qu'un gène "transplanté" dans une autre espèce pouvait devenir un élément définitif du patrimoine génétique d'un receveur d'une autre espèce (Houdebine, 1998 ; Houdebine, 2016).

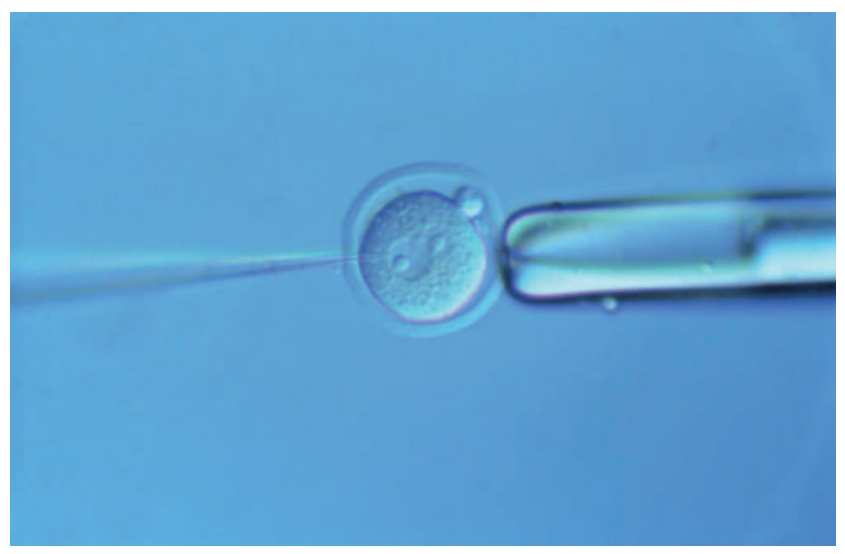

Figure 1 : Création d'un animal transgénique par injection in ovo d'un ADN cloné à l'aide d'une micropipette de verre. Après l'injection, le pronucléus apparaît un peu dilaté. Dans le cas représenté l'embryon est celui d'une souris. Sa taille est d'environ 80 microns.

Depuis cette date des milliers de souris et de rats transgéniques (ainsi que quelques hamsters, lapins ou autres petits mammifères) ont été produits, ce qui a considérablement contribué à faire progresser l'analyse et la compréhension de la régulation de l'expression des gènes.

L'injection d'ADN exogène in ovo a aussi été utilisée pour faire produire par l'organisme d'un animal (lapin, chèvre, mouton, etc...) une protéine n'appartenant pas au "répertoire" normal de l'espèce en question (une stratégie parfois désignée sous le vocable de "gene pharming" ou "gene farming").

La transgénèse par transfert horizontal d'ADN d'une espèce "donneuse" à une espèce "receveuse" trouve d'importantes applications au niveau zootechnique, comme nous l'expliquerons plus loin, mais elle a malheureusement quelques inconvénients. Par exemple, on ne peut pas savoir précisément quel(s)

1- Emmanuelle Charpentier est une ancienne élève de l'Université Pierre \& Marie Curie et de l'Institut Pasteur. Elle a séjourné et travaillé successivement aux États-Unis, en Suède et surtout en Allemagne, où elle dirige aujourd'hui le Max Planck Institut de Berlin, spécialisé dans les maladies infectieuses. Jennifer Doudna est professeure de biochimie et de biologie moléculaire à l'Université de Californie à Berkeley.

2- La traduction de l'expression "genome editing" en "édition du génome" pourrait être discutée car le verbe anglais "to edit" n'a pas le même sens que le verbe français "éditer" en dépit d'une certaine ressemblance. A sa place, et comme suggéré par certaines Académies francophones, nous avons envisagé d'utiliser le mot "réécriture du génome" mais il apparaît aujourd'hui que l'expression "gene editing" ou "genome editing" est universellement acceptée. Nous suivrons la tendance ! 3- Dans cet article nous faisons uniquement référence aux espèces de mammifères domestiques. Les stratégies utilisées pour modifier le génome des espèces aviaires sont détaillées dans un article récent du Bulletin de l'Académie Vétérinaire de France (voir Ducos et al. 2020).

4- C'est-à-dire une séquence codante, avec un promoteur en amont (en 5'), éventuellement un enhancer, une TATAbox, une CATbox, etc.). 
sera (seront) le (ou les) site(s) d'insertion des ADN transgéniques ni le nombre de copies insérées de manière stable dans le génome receveur. Un autre inconvénient est que certains transgènes implantés par hasard dans certaines régions du génome seront fortement exprimés, et exprimés de manière constitutive (c'est-à-dire non-régulée), tandis que d'autres seront exprimés de manière aléatoire et/ou seulement dans certaines cellules de l'organisme (extinction par "imprinting" par exemple). Enfin, l'expérience enseigne que les transgènes produits par injection directe in ovo sont souvent perdus ou modifiés structurellement après quelques générations.

En conséquence de ces inconvénients et en application de la législation actuellement en vigueur (Directive européenne 2001/18/CE du 12 mars 2001 et arrêt de la Cour de Justice de l'Union européenne du 25 juillet 2018 - voir plus loin) les organismes génétiquement modifiés (OGM) (ou génétiquement "édités") ne peuvent être élevés qu'à des fins purement expérimentales et en confinement ou pour la production de molécules d'intérêt pharmacologique. La raison principale qui interdit la dissémination des animaux transgéniques (et les place donc hors-commerce) est liée au fait qu'ils sont considérés comme génétiquement instables et par conséquent non standardisés (principe de précaution). On ne peut pas davantage mettre les produits dérivés de tels animaux transgéniques (lait, viande, etc...) directement dans la chaine alimentaire (Regnault-Roger et al. 2017 ; Houdebine, 2016).
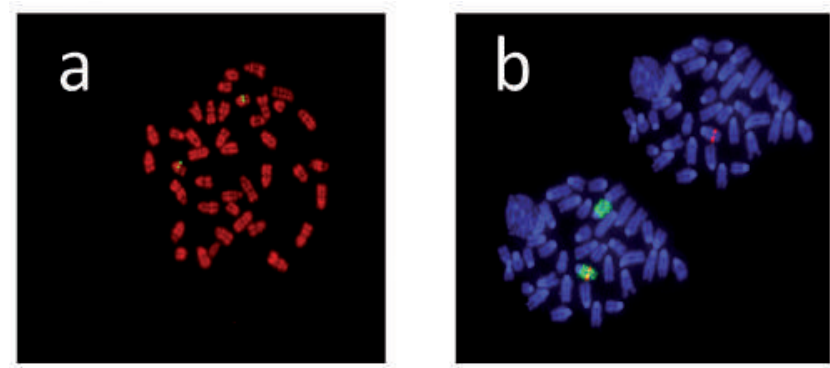

Figure 2

a - En utilisant les techniques d'hybridation in situ, avec sonde fluorescente (FISH), on peut repérer un transgène sur un caryotype et savoir s'il est hémi (une copie) ou homozygote (deux copies).

b- En utilisant des sondes moléculaires spécifiques d'une paire de chromosome particulière (couleur verte) on peut en déduire le site d'implantation d'un transgène (rouge sur chromosome bleu - chromosome 12 dans ce cas) et vérifier s'il est stable. (souris - Tg H2 - Chr 17) - hémi et homozygote.

\section{L'utilisation de lentivirus comme vecteurs pour l'intégration d'ADN exogènes dans le génome des animaux domestiques}

Bien que réalisée avec succès dans la plupart des espèces de mammifères domestiques de grande taille et dans plusieurs laboratoires à travers le monde, la transgénèse par injection d'ADN in ovo est toujours restée d'un très faible rendement et seul un faible pourcentage des embryons traités se sont finalement matérialisés en un nouveau-né transgénique. Les chercheurs ont donc essayé des stratégies alternatives pour parvenir au même but, avec un meilleur rendement, et c'est tout naturellement que l'idée est venue de s'adresser aux lentivirus. Les lentivirus sont des rétrovirus ayant un ARN encapsulé mesurant entre 80 et $100 \mathrm{~nm}$. Ils peuvent être modifiés génétiquement in vitro et préserver leur capacité de transduire des cellules qui ne se divisent pas $^{5}$. De tels lentivirus peuvent pénétrer dans le noyau des cellules somatiques et germinales d'un hôte permissif et y déposer leur ARN. Comme ils disposent d'une transcriptase inverse, l'ARN viral peut alors être rétro-transcrit en copies $\mathrm{ADN}$ qui s'intègrent dans le génome des cellules hôtes sous forme de nombreuses copies (des provirus). Si l'on considère ces deux aspects, les lentivirus constituent donc de bons candidats pour jouer le rôle de vecteur pour la transgénèse. Pour mettre à profit la stratégie, il suffit de construire in vitro un lentivirus inoffensif à partir d'un clone correspondant à un gène d'intérêt et de le laisser s'insérer sous la forme d'ADN rétro-transcrit dans les cellules ciblées. De telles expériences ont été réalisées aux USA notamment dans le laboratoire de Rudolf Jaenisch (Whitehead Institute Cambridge, MA 02142 - USA). La plupart des expériences ont été réalisées sur des embryons de souris, avec un lentivirus placé sous le contrôle d'un promoteur ubiquitaire (celui de la phosphoglycérate kinase, LV-PGK - par exemple) mais d'autres expériences ont été faites avec des embryons porcins ou même bovins qui ont conduit à des pourcentages d'intégration très intéressants (70\%) d'animaux ayant incorporé dans leur génome, de manière stable, une ou plusieurs copies du lentivirus en question (Lois et al. 2002 ; Hofmann et al. 2003 ; Fässler, 2004). Dans une expérience les chercheurs ont rapporté que sur 46 porcelets nés, 32 (70\%) avaient intégré dans leur génome au moins une copie de l'ADN transgénique et 30 (65\%) de ces porcelets exprimaient le transgène (matérialisé par la fluorescence verte d'une protéine utilisée comme marqueur GFP). Certaines expériences ont été réalisées avec le même succès en injectant une suspension de lentivirus directement dans l'espace périvitellin ou en laissant les embryons incuber dans cette même suspension pendant quelques heures.

Fait important, les chercheurs ont montré que les transgènes provenant de transfections par lentivirus pouvaient ensuite être transmis, sans modifications, par la lignée germinale et que ces transgènes pouvaient, dans certains cas, n'être exprimés que dans les tissus où les promoteurs étaient "ouverts". L'expression transgénique spécifique aux tissus a été obtenue en infectant les embryons porcins avec des vecteurs lentiviraux contenant le promoteur de la kératine humaine K14 (LV-K14). L'infection d'ovocytes bovins, avant ou après la fécondation in vitro, par LV-PGK a entraîné l'expression transgénique chez $45 \%$ et $92 \%$ des embryons infectés, respectivement : un rendement très élevé. Malheureusement la taille de l'insert ADN transductible par les lentivirus (le transgène proprement dit) est limitée à 8/9 kb. C'est vraiment très (trop) peu pour la plupart des projets expérimentaux. Il faut néanmoins retenir que la méthode est si simple à mettre en œuvre et si efficace qu'elle pourrait sans doute encore trouver des applications.

5- La transfection consiste à introduire, directement, par exemple avec une pipette en verre, un ADN étranger dans une cellule eucaryote cultivée in vitro. La transduction consiste à transférer une information génétique (un ADN) d'une cellule à une autre par l'intermédiaire d'un vecteur (virus ou phage par exemple). 


\section{Les cellules souches embryonnaires : des outils exceptionnels pour modifier le génome (de la souris)}

Au cours des années 1980, à la suite des travaux de Martin Evans, Mario Capecchi \& Oliver Smithies ${ }^{6}$ et de nombreux autres collègues dont L. C. Stevens, du Jackson Laboratory - Bar Harbor ME-USA, les généticiens ont développé des techniques très avancées de modifications du génome de la souris en travaillant sur des cellules souches embryonnaires (Embronic Stem cells ou ES cells). Ces cellules, dérivées de la masse cellulaire interne (inner cell mass) d'embryons au stade de blastocyste, présentent le double avantage de pouvoir être cultivées in vitro, pendant plusieurs générations, sans se différencier, et de finalement se différencier en tous types de tissus lorsqu'elles sont replacées dans la cavité d'un blastocyste receveur, pour participer à la formation d'un embryon chimérique (cellules normales $\leftrightarrow$ cellules ES). Un autre avantage, et non des moindres, est que les cellules ES, pendant leur séjour in vitro, peuvent être manipulées comme des cellules somatiques et, en particulier, elles peuvent être mises au contact d'agents mutagènes ou transfectées avec de l'ADN exogène, génétiquement modifié ou non, dans le but d'obtenir une recombinaison avec un segment homologue de l'ADN des cellules ES. Les cellules ES peuvent aussi être sélectionnées sur leur aptitude à se multiplier dans certains milieux sélectifs artificiels, comme de simples cellules somatiques. Enfin, elles peuvent facilement et durablement être préservées sous forme congelées dans l'azote liquide?

De nos jours, en utilisant les cellules souches embryonnaires (les ES cells), les généticiens de la souris peuvent pratiquement tout faire en matière de modification génomique pour finalement produire un animal (une souris !) qu'ils pourront étudier à loisir. En utilisant les cellules ES on peut en effet déléter, ajouter, dupliquer, inverser un segment d'ADN de longueur variable, on peut remplacer un seul nucléotide (symbole $n t=$ une paire de base) par n'importe lequel des quatre autres (base editing), on peut programmer une modification et faire en sorte qu'elle devienne effective (dans les cellules germinales ou dans les cellules somatiques d'un certain tissu) uniquement quand l'expérimentateur le décidera (mutations conditionnelles) : le nec plus ultra ....! Malheureusement, les techniques de modification, d'édition du génome faisant appel aux cellules ES sont longtemps restées limitées à la souris car il n'existait pas de véritable équivalent des cellules ES dans d'autres espèces. Récemment, une méthode a été proposée pour développer un équivalent des cellules ES dans d'autres espèces que la seule souris : il s'agit de cellules souches pluripotentes induites (induced pluripotent stem cells) ou iPS cells ${ }^{8}$. Ces IPS cells dérivent de cellules adultes, donc différenciées, que l'on a fait retourner à l'état de cellules indifférenciées (et par conséquent pluripotentes) par ré-activation, in vitro, de quelques gènes $(5 / 6)$ ) (oncogènes pour la plupart) produisant des facteurs de transcription. Ces iPScells présentent de l'intérêt pour modéliser certaines pathologies humaines et ouvrent la voie au développement de stratégies innovantes en médecine régénérative. Par contre, elles ont été très peu utilisées (si même elles l'ont été ... ?) en génétique des animaux domestiques car leur production est onéreuse et ne présente pas d'avantages particuliers par rapport à d'autres techniques récemment développées que nous allons maintenant décrire.

\section{Les techniques faisant appel au transfert de noyau de cellules somatiques SCNT}

Le transfert de noyaux de cellules somatique (Somatic Cell Nuclear Transfer ou SCNT) a été utilisée avec succès chez le porc et chez les ruminants. Comme le nom l'indique, la technique consiste à disséquer mécaniquement le noyau de cellules somatiques maintenues en culture in vitro, sous forme de lignée, et à le transférer intact dans le cytoplasme d'un ovocyte parvenu au stade métaphase-II, et énucléé, dans le but de reconstituer un embryon génétiquement identique aux cellules somatiques de la lignée cultivée in vitro. Pendant le passage in vitro, l'ADN des cellules somatiques peut être modifié par n'importe quelle technique d'ingénierie génétique cellulaire (transfection, mutagénèse, recombinaison homologue, etc.) comme on pourrait le faire avec les cellules ES décrites ci-dessus (Schibler, 2020). Le succès du clonage d'un animal entier, la brebis "Dolly" en Écosse (Wilmut et al.1997) ou la vêle "Marguerite" en France, à Jouy-en-Josas (Chesne et al. 1993), à partir d noyau de cellules différenciées (ou en voie de différenciation) a démontré que les gènes inactivés lors de la différenciation tissulaire pouvaient être réactivés par un processus de reprogrammation nucléaire. Cela a fait naître l'espoir que la technique SCNT pourrait être utilisée pour produire des animaux dont le génome aurait été modifié à l'occasion d'un passage in vitro. Plusieurs expériences ont été entreprises et certaines ont été couronnées de succès (Hauschild et al. 2011). Malheureusement, le développement $a b$ utero de ruminants et porcins clonés (car le transfert nucléaire comporte une étape de clonage) pose encore des problèmes qui limitent sérieusement le champ d'investigation. Il semblerait en effet que la reprogrammation de l'héritage épigénétique soit incomplète lors du transfert nucléaire.

Tout comme dans le cas des iPS cells, le développement rapide des techniques faisant usage d'endonucléases programmables (voir ci-dessous) porte aujourd'hui ombrage à la technique SCNT et il n'est pas sûr qu'elle ait encore un avenir. Nous l'aurons donc citée à titre historique... (Lee et al. 2020).

\section{Les techniques faisant usage d'endonucléases programmables}

Au cours des dix dernières années, une approche originale a été développée par plusieurs laboratoires dans le but de produire, avec précision et efficacité, des mutations ciblées sur une région précise du génome. Cette approche fait usage de molécules

6- Tous les trois Prix Nobel de Biologie/Médecine en 2007 pour la mise au point de techniques permettant l'inactivation de gènes ciblés ; une technique qui, à son tour, a entraîné une série de découvertes à présent appliquées dans de nombreux domaines de biomédecine.

7- Le chapitre 8 du livre Genetics of the Mouse - Transgenesis and Genome manipulations - Springer Verlag 2015, est tout entier consacré à la description des cellules ES et à la présentation de leur énorme potentiel chez la souris. Ce chapitre est accessible par internet : https://www.springer.com/gp/book/9783662442869

8- Cette découverte a valu le prix Nobel de Biologie/Médecine 2012 au chercheur japonais Shinya Yamanaka. 
artificielles d'un nouveau type, qui portent le nom générique d'endonucléases programmables parce qu'elles peuvent être synthétisées à la demande (en franglais "customisées"), à partir de sous-unités simples, en utilisant les techniques modernes d'ingénierie des protéines ${ }^{9}$. Ces endonucléases programmables associent toujours :

- un domaine spécifique de reconnaissance et de liaison à une séquence d'ADN prédéfinie (un DNA binding domain) qui comporte environ 18/24 nucléotides, rarement plus et,

- un domaine de clivage (un cleavage domain) ou site de coupure. Ce domaine est non spécifique et il est en général emprunté à la bactérie Flavobacterium okeanokoites (symbole FokI). Il mesure entre 5 et $7 \mathrm{pb}$ (Figure 3). Deux types d'endonucléases programmables méritent de retenir l'attention parce qu'elles ont été utilisées plus que les autres : il s'agit des nucléases dites à "doigts de zinc" ou Zinc Finger Nuclease - ZFN - et des nucléases effectrices de type "activateur de transcription" ou Transcription Activator-Like Effector Nuclease - TALEN". L'association des endonucléases ZF ou TALE à la cible d'ADN entraîne un changement de conformation de ces molécules lequel active la coupure.

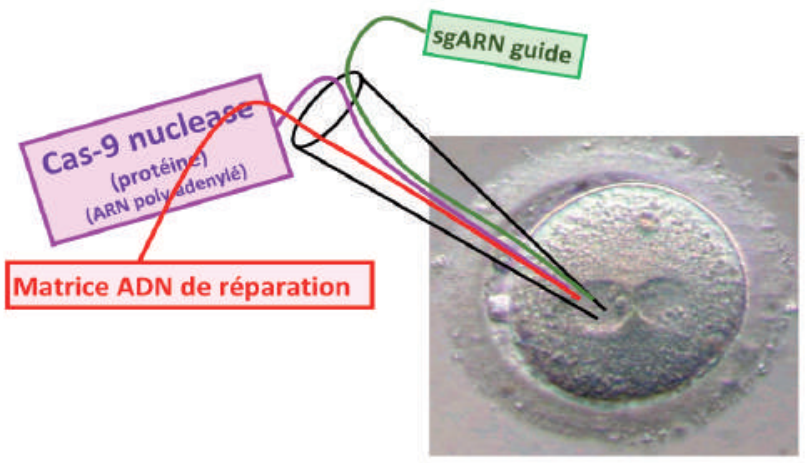

Figure 3 : La technique CRISPR-Cas9 consiste à micro-injecter, dans un embryon au stade 1, la nucléase Cas9 (ou son ARN polyadénylé) et l'ARN guide ( $g \mathrm{~g} A R N$ ou gARN) ciblant une séquence précise de l'ADN. L'ARN guide (gARN ou sgARN), complémentaire de la séquence-cible, forme un complexe avec l'ARN, il le stabilise, puis le guide vers la cible et active l'endonucléase Cas9 laquelle clive l'ADN de façon spécifique (coupure double brin).

Pour la production de mutations ciblées, deux ZFN (ou TALEN) complémentaires doivent être synthétisées, chacune reconnaissant une séquence d'ADN spécifique de 9 à 12 pb de part et d'autre d'une séquence de 5 à 7 pb définissant la région FokI (le site de coupure. Lorsque ces deux nucléases sont injectées dans une cellule en cours de division (disons "mitotiquement active") ou bien dans le noyau d'un embryon stade 1, elles se positionnent de chaque côté du site ciblé, une sur chaque brin, et FokI effectue les coupures double brin. La possibilité de choisir, à volonté, la séquence de l'ADN génomique double brin permet de cibler une coupure au nucléotide près et plus le site est "large", plus le ciblage est précis.
Ces techniques d'induction de coupures double-brin dans l'ADN ont montré des avantages pour la production d'une variété de mutations sur des sites ciblés dans plusieurs espèces couramment utilisées par les généticiens, par exemple Arabidopsis thaliana, Caenorhabditis elegans, Drosophila melanogaster et le poisson zèbre (Danio rerio), pour n'en citer que quelques-unes. Récemment, les techniques en question ont été adaptées avec succès à la production de mutations ciblées chez les mammifères, principalement chez le rat (Geurts et al. 2009), la souris (Carbery et al. 2010), et d'autres espèces domestiques (revues dans Gaj et al. 2013; Kim \& Kim, 2014) et même chez l'embryon humain ${ }^{10}$.

Les endonucléases programmables sont comparables à de véritables ciseaux moléculaires qui permettraient de faire des coupures ciblées dans l'ADN.

Une fois les coupures effectuées dans l'ADN, la cellule a naturellement tendance à réparer les "dommages" et deux situations sont alors possibles (Figure 4) qui ont des conséquences radicalement différentes :

- ou bien la réparation de l'ADN ne se fait pas du tout ou bien elle se fait mal (Non-homologous end joining - NHEJ (= jonction d'extrémités non-homologues - Figure 4) et l'ADN ciblé (le segment génomique impacté) porte alors une mutation (en général une délétion de plus ou moins grande taille, parfois une insertion de quelques nucléotides ${ }^{11}$ ). Les conséquences de cette coupure sont assez imprévisibles mais, si elle se produisent dans une région critique (dans un gène, dans un promoteur ...etc.) le gène ainsi muté n'est plus fonctionnel. C'est un knockout.

- ou bien la réparation de l'ADN est dirigée - ou guidée - par addition d'une matrice d'ADN exogène qu'une polymérase recopie plus ou moins fidèlement (Homology directed repair ou HDR sur la Figure). Dans ce deuxième cas, si la séquence de l'ADN qui sert de matrice est normale (c'est à dire native) il peut y avoir réparation ad integrum (l'expérience dans ce cas a évidemment peu d'intérêt !). En revanche, si l'ADN matrice a une séquence qui correspond à un gène d'intérêt ou une séquence potentiellement intéressante et à évaluer, alors la mutation est un knock-in.

La structure moléculaire des mutations ponctuelles induites par les ZF ou les TALE nucléases doit être analysée et confirmée par séquençage direct de la région. Cela permet de trier les mutations en fonction de leur intérêt potentiel dans la suite du projet expérimental. Comme nous le verrons ci-dessous, plusieurs mutations ciblées ont été induites chez les mammifères domestiques en utilisant les endonucléases programmables de type ZF ou TALE et bien d'autres pourraient l'être dans un proche avenir. La synthèse d'endonucléases customisées se fait aujourd'hui sur simple commande à certaines firmes spécialisées mais elle est relativement coûteuse. Depuis l'avènement de la stratégie CRISPR-Cas9 (décrite ci-dessous) l'utilisation des ZFPs et des TALENs est pratiquement abandonnée.

9- Le laboratoire du Professeur B. Dujon (Institut Pasteur et Sorbonne-Université), dans lequel travaillait aussi le généticien A. Choulika, a beaucoup contribué à la mise au point d'endonucléases programmables.

10- En 2018, le chercheur chinois Dr He Jiankui, a annoncé la naissance de jumelles génétiquement modifiées (par lui même) par la méthode CRISPR-Cas9 afin de devenir résistantes au virus du sida (KO du co-récepteur CCR5). Le chercheur a été condamné par la justice de son pays.

11- Les spécialistes parlent d'indels (= insertions/délétions). 


\section{CRISPR/Cas9}

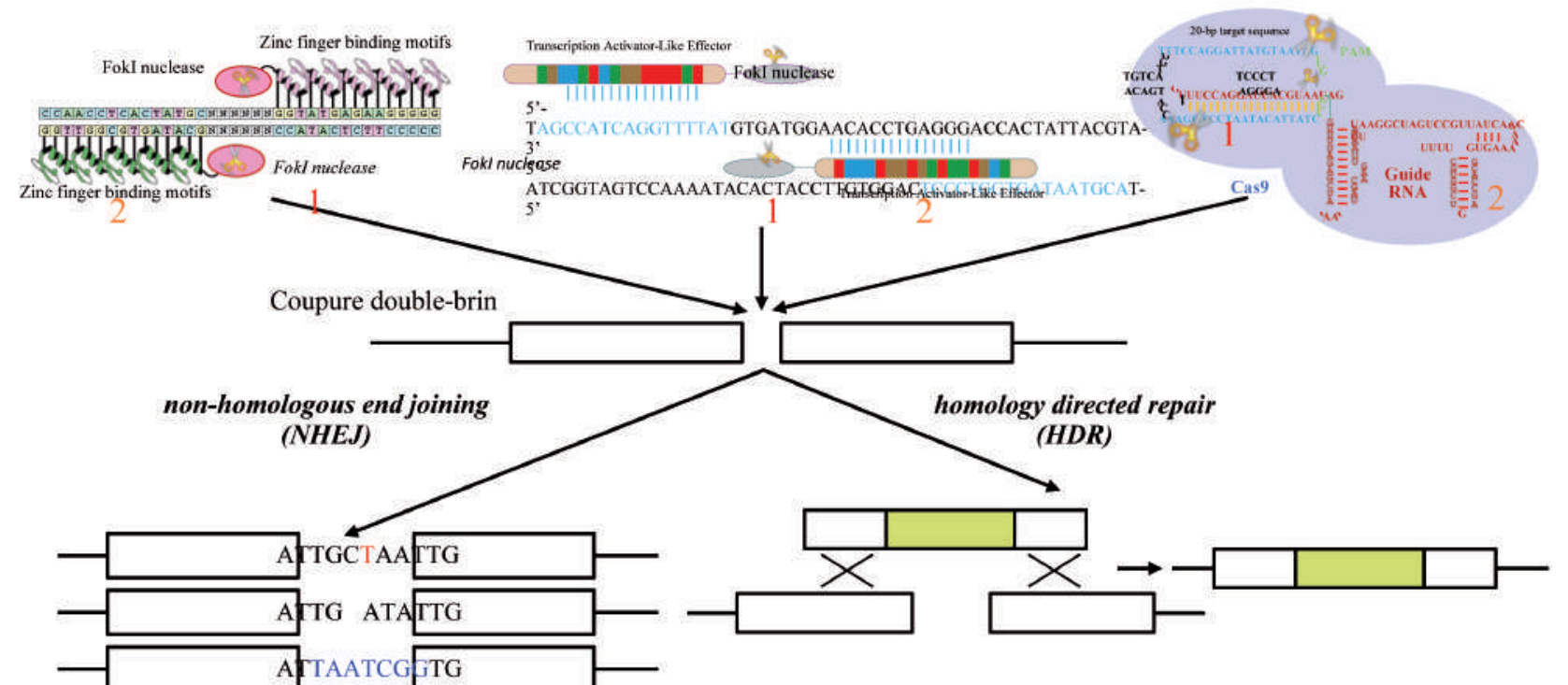

Knockout (KO)

Knock-in (KI)

Figure 4 : (schéma aimablement fournie par Dr T. Mashimo - Université d'Osaka - Mashimo et al. 2013)

Les endonucléases programmées ZFN ou TALEN (en haut à gauche et au centre) reconnaissent un site d'attachement à l'ADN et procèdent, à cet endroit précis, à une coupure double brin. L'endonucléase Cas9 (à droite), guidée par un ARN spécifique procède de la même façon.

L'ARN guide (gARN), complémentaire de la séquence-cible, forme un complexe avec le tracrARN, il le stabilise, puis le guide vers la cible et active l'endonucléase Cas9 laquelle clive l'ADN de façon spécifique (coupure double brin) en amont d'une séquence PAM (Protospacer Adaptor Motif) localisée sur l'ADN génomique.

Une fois les coupures effectuées dans les régions ciblées deux cas peuvent se produire selon que la/les coupures sont ou non réparées. Si la coupure n'est pas réparée, l'ADN comporte une mutation (souvent une micro-délétion - parfois une micro-insertion) affectant quelques nucléotides. Cette mutation est en général incompatible avec le maintien de la fonction de la protéine et c'est un knockout (un allèle inactif). Dans certains cas, les enzymes impliquées dans le maintien de l'intégrité de l'ADN réparent ce dernier plus ou moins complètement. La réparation se fait rarement ad integrum mais cela peut se produire lorsqu'on fournit in situ un ADN matrice de réparation (ou un oligo-nucléotide). La mutation est alors un knock-in.

Lorsque l'injection se fait dans le cytoplasme de l'embryon les deux chromosomes d'une même paire peuvent être impactés par des coupures. Cela favorise la production d'homozygotes en une seule étape. C'est un avantage (gain de temps) considérable dans certaines espèces domestiques.

\section{La l'édition du génome façon Charpentier \& Doudna : la stratégie CRISPR-Cas9}

La méthode de réécriture du génome des mammifères la plus communément utilisée de nos jours est celle qui s'inspire des travaux des deux récipiendaires du Prix Nobel : E. Charpentier et J. Doudna (Doudna \& Charpentier, 2014). Pour des raisons historiques, cette méthode est connue sous le vocable "Clustered Regularly Interspaced Short Palindromic Repeats" - en abrégé : CRISPR-Cas9. Cette désignation fait référence à un système d'immunité acquise qui confère à certaines espèces bactériennes une résistance vis-à-vis de certains agents infectieux tels que plasmides et/ou phages ${ }^{12}$.

Comme nous l'avons déjà dit la première étape de "l'édition" d'un segment génomique avec le système CRISPR-Cas9 est la coupure initiale. Pour cela, il faut injecter dans l'œuf, au stade 1, toujours à l'aide d'une micropipette de verre, deux types de molécules :
- d'une part une endonucléase appelée Cas9, qui fait des coupures double-brin dans l'ADN génomique, et

- d'autre part un court ARN dont la séquence nucléotidique correspond (en partie) à celle de la séquence d'ADN ciblée pour la coupure double brin. La taille de ce genre d'ARNs est de 20 à 25 nucléotides et on leur donne le nom générique de gARN (ARN guide) parfois de sgARN. Ainsi, on peut dire qu'entre Cas9, l'endonucléase, et le gARN il s'établit une sorte de "partenariat moléculaire" dans l'œuf injecté, partenariat dont la mission est de couper l'ADN à un endroit bien précis. Dans cette affaire, le gARN joue le rôle de "poisson pilote", pour conduire l'endonucléase Cas9 à pied d'œuvre, à l'endroit même où elle doit agir (le "DNA binding domain"), et il est important de noter que le gARN peut être synthétisé au laboratoire, dans la perspective d'une expérience précise, unique, "à la demande" ! De nos jours, le gARN peut être commandé à un fournisseur commercial (avec Cas-9 et tous les tampons et autres ingrédients

12- Emmanuelle Charpentier et Jennifer Doudna ont fait, chacune, une conférence publique à l'Académie des Sciences, à propos de leurs découvertes et de la mise au point de la méthode CRISPR-Cas9. Nous y renvoyons le lecteur intéressé. https://www.academie-sciences.fr/fr/Seances-publiques/la-revolution-crispr-cas9.html 
nécessaires à la première étape) sous forme de "kit" prêt à l'emploi (par exemple Cellectis ${ }^{\mathrm{TM}}$-Horizon ${ }^{\mathrm{TM}}$ etc.).

En guise d'épilogue à cette description de la méthode CRISPR-Cas 9 on peut faire quelques remarques :

- la méthode en question fait appel à un petit ARN pour le ciblage de la coupure : une molécule bien plus facile (et surtout bien moins onéreuse) à synthétiser qu'une endonucléase de type ZF ou TALE.

- la méthode peut s'appliquer à plusieurs espèces domestiques car elle ne fait appel à aucun équipement spécifique. Tout laboratoire ayant l'expérience et la pratique de la manipulation des embryons de mammifères, à un stade précoce, peut "éditer" un segment génomique quand et comme il le souhaite.

- enfin, si l'injection de l'ARN guide et de l'endonucléase Cas9 se fait dans une cellule où les deux chromosomes d'une même paire sont accessibles, alors l'intervention peut aboutir à la création d'un embryon homozygote : il suffit pour cela que les deux "cibles" soit impactées ${ }^{13}$. Cela représente souvent un avantage important (gain du temps de deux générations).

\section{POURQUOI ÉDITER LE GÉNOME DES MAM- MIFĖRES DOMESTIQUES ?}

De nombreuses modifications du génome des animaux domestiques ont été rapportées dans les revues spécialisées au cours des trente dernières années et il est plus que probable que d'autres, plus originales et plus sophistiquées encore, seront décrites dans les années à venir si on considère que les techniques d'édition du génome, comme nous l'avons expliqué dans la section précédente, évoluent vers toujours plus de simplicité, plus de fiabilité et tout cela pour un coût toujours plus faible. On est alors amené à s'interroger sur l'intérêt potentiel de ces modifications?

Pour répondre à cette question nous avons rassemblé ici quelques exemples choisis parmi ceux qui ont été les plus récemment publiés pour illustrer la variété des possibilités qui sont offertes au généticien (et au vétérinaire !) en matière d'édition du génome et leur intérêt. Il nous a paru plus raisonnable de classer ces exemples en fonction de leur intérêt et du but recherché plutôt qu'en fonction de la technique utilisée. La prise en compte des exemples présentés permettra au lecteur de réaliser qu'une étape importante est en train de s'accomplir en matière de génétique et de zootechnie dont les conséquences seront, à l'évidence, très importantes.

\section{L'utilisation de la transgénèse in ovo pour produire en quantité des protéines d'intérêt pharmaceutique ou à haute valeur ajoutée}

Comme nous l'avons déjà mentionné, une des modifications les plus simples que l'on puisse réaliser dans le génome d'un mammifère consiste à ajouter, par transgénèse in ovo, un ADN exogène (un gène cloné par exemple), tout en faisant le nécessaire pour que ce dernier soit correctement transcrit puis traduit sous forme de protéine. Un raffinement supplémentaire consiste à faire en sorte que le promoteur de ce transgène soit choisi de telle manière que la protéine codée par le transgène soit secrétée uniquement dans le lait, ou uniquement dans le plasma/sérum sanguin ou éventuellement dans un autre tissu comme le muscle, le tissu adipeux, etc.

Cette idée a été exploitée dès 1985, soit seulement cinq ans après la naissance de la première souris transgénique, avec la production de porcs, de chèvres et de brebis transgéniques pour des gènes qui codent certaines hormones ou certains facteurs de croissance citons : l'hormone de croissance (GH - Growth hormone), l'IGF1 (Insulin-like Growth Factor), l'Erythropoïétine (EPO), certains facteurs de coagulation, des interleukines, etc. (revues dans Houdebine, 1998; Houdebine, 2016; Houdebine, 2018; Kalds P et al. 2019).

Ces animaux transgéniques de "première génération" avaient les défauts que nous avons mentionnés plus haut (instabilité, transcription "capricieuse" et parfois perte ou extinction du transgène. Mais beaucoup d'entre eux ont malgré tout été exploités à des fins de "gene pharming" et certains le sont (ou pourraient l'être) encore.

Des animaux transgéniques plus fiables et mieux standardisés ont été produit plus récemment parmi lesquels on peut citer :

- des vaches transgéniques exprimant dans leur lait, le gène humain de l'alpha-Lactalbumine ALA, (jusqu'à 1,55 g/L), le rendant capable de complémenter ("d'humaniser") le lait de vache, qui est un lait pauvre en cette composante (Wang et al. 2008 ; Whitelaw et al. 2016 ; Kalds et al. 2019).

- des chèvres homozygotes pour un allèle non-fonctionnel (knockout) de la beta-Lactoglobuline (BLG) une protéine allergisante (Zhou et al. 2017).

- des brebis (et bientôt des vaches) transgéniques, exprimant dans leur lait deux gènes clonés à partir de la glande pinéale des moutons et impliqués, tous les deux, dans la synthèse de la mélatonine $=$ un antioxydant puissant (l'Acétylsérotonine Méthyltransférase - ASMT- d'une part et l'Arylalkylamine $\mathrm{N}$-acétyltransférase - AANAT d'autre part) (Ma et al. 2017). Ces laits "supplémentés" (ou corrigés) par transgénèse ont une importante valeur nutritionnelle et médicinale.

D'autres exemples pourraient être cités pour souligner l'intérêt incomparable des animaux transgéniques pour des gènes clonés provenant d'une autre espèce même si ces transgènes sont aussi ceux qui posent le plus de problèmes (Clark \& Whitelaw, 2013). Les seules limites à cette stratégie sont, d'une part, que la physiologie de l'animal transgénique F0 ne soit pas trop perturbée par le ou les produit(s) du transgène exogène et, d'autre part, que l'animal transgénique fondateur (souvent noté FO) soit fertile. A ces deux réserves près chacun comprendra qu'en se rendant capable d'engendrer de tels animaux transgéniques l'homme a considérablement élargi les limites et avantages de la domestication. Désormais, ce ne sont plus seulement la production de lait, de laine, de viande, d'œufs, etc. que l'on peut exploiter à partir des animaux domestiques traditionnels mais ce sont aussi des molécules à haute valeur ajoutée que l'on peut produire en exploitant la transgénèse.

13- Notons dans ce cas précis que chaque mutation étant un événement unique et indépendant, les individus de ce type devraient plutôt être qualifiés de "double hétérozygotes" (pour deux allèles différents bien que de même type). 


\section{Modifier le génome pour agir sur la sensibilité des animaux aux maladies infectieuses}

Dans un précédent numéro du Bulletin de l'Académie Vétérinaire de France (Guénet, 2017) nous avons discuté de l'intérêt qu'il y aurait de pouvoir modifier le génome des animaux domestiques afin de rendre ces derniers plus résistants aux maladies infectieuses. Aujourd'hui nous pouvons confirmer que cette voie de recherche est plus que jamais active et cela dans plusieurs laboratoires, notamment en Chine et au Royaume Uni (UK) aux Etats-Unis (USA). Voici quelques exemples.

Il est désormais établi que le récepteur auquel se fixe l'artérivirus responsable du syndrome dysgénésique et respiratoire porcin (SDRP) (Porcine Reproductive and Respiratory Syndrome - PRRS) est la macrophage specific protein CD163 et il vient d'être démontré que la délétion de l'exon 7 du seul domaine 5 de cette protéine (par la méthode CRISPR-Cas 9) empêche la pénétration du virus dans les cellules tandis que toutes les autres fonctions de la protéine "éditée" sont conservées (Burkard et al. 2017). Ainsi, une nouvelle lignée de porc résistante au virus du PRRS a pu être créée, qui ne diffère de la lignée traditionnelle (sensible) que par la délétion d'un court segment de son génome. Un raffinement extrême!

Il est probable que des situations analogues à celle du virus SDRP existent à l'état naturel, pour d'autres agents pathogènes et/ou dans d'autres espèces domestiques, mais qu'elles attendent d'être révélées, par exemple à la suite d'une discrète modification du génome, mais ces situations restent pour l'instant à découvrir. En tous cas, s'il est possible par une simple modification du génome ou par quelque stratagème que ce soit d'empêcher un virus de pénétrer dans les cellules d'un hôte potentiel, ou d'y accomplir son cycle normal, alors on peut s'attendre à ce que le pouvoir infectieux de ce virus soit sérieusement compromis ${ }^{14}$.

Dans le même contexte, il a également été démontré que "l'édition" du segment génomique qui code la protéine RELA/p65, impliquée dans la cascade cytokinique NF-b, pouvait avoir des conséquences importantes sur la sévérité des symptômes de la peste porcine africaine (ASF). Lorsque le segment génomique du porc domestique (Sus scrofa) qui code cette protéine est remplacé par celui du phacochère (Phacochoerus africanus) ou du potamochère (Potamochoerus larvatus), deux suidés sauvages vivant en Afrique et "cousins génétiques" du porc domestique, alors les symptômes de la maladie sont beaucoup moins sévères et les animaux survivent, ce qui permet de maintenir un élevage sans trop de perte ${ }^{15}$ (Lillico et al. 2013 ; Lillico et al. 2016).

Il a aussi été observé que des vaches transgéniques, chez lesquelles le gène codant la beta-caséine (une protéine exprimée dans le lait) a été remplacé par celui du lysozyme humain (knock-in hLYZ) présentaient une résistance accrue à Staphylococcus aureus et que, de ce fait, elles développaient moins de mammites (Liu et al. 2014).

Notons enfin que des chèvres homozygotes pour une mutation knockout ou pour une délétion qui empêche la synthèse de la protéine Prion $\left(\mathrm{PrP}^{\mathrm{C}}\right)$ ne propagent pas les prions et sont résistantes à la tremblante (Salvesen et al. 2020).

Les exemples que nous venons de donner doivent être considérés comme des étapes très importantes en médecine vétérinaire car ils matérialisent une nouvelle approche en matière de prophylaxie des maladies infectieuses. Jusqu'à présent, face aux maladies infectieuses (surtout d'origine virale), les vétérinaires pouvaient éventuellement proposer des vaccins, plus ou moins bons, des médicaments chimiques et notamment des antibiotiques eux aussi plus ou moins efficaces, des sulfamides, etc. Désormais, ils pourront recommander de choisir (si elle existe) une race génétiquement modifiée offrant une "résistance innée" ! Certes, pour que ceci soit possible il faudra d'abord identifier le ou les gène(s) dont le rôle est fondamental dans le cycle viral (gènes que les généticiens désignent sous le nom de "candidats") et mettre ensuite au point une stratégie de modification du génome qui implique ces gènes. Ce sera à coup sûr une voie d'avenir pour la recherche vétérinaire de demain !

\section{Modifier le génome pour augmenter les produc- tions animales}

La myostatine (MSTN) est un facteur de croissance de la famille des TGF a-1 qui est exprimé dans les cellules musculaires striées (essentiellement les muscles squelettiques) et en limite la croissance chez l'individu normal. Plusieurs mutations affectant le gène MSTN ont été identifiées chez les mammifères domestiques (bovins, ovins et porcins) et parmi ces mutations, la plus connue "est celle qui produit le phénotype "culard" ou "callipyge" qui se traduit par une hypertrophie importante (20 à 25\%) des masses musculaires du dos et des fessiers ${ }^{16}$. Le syndrome est bien caractérisé dans la race Piétrain pour le porc, dans la race Texel en ce qui concerne les moutons et dans les races blanc-bleu belge ou Piémontaise chez les bovins : quelle que soit l'espèce, c'est le même gène qui est concerné (Grobet et al. 1997 ; Zhang et al. 2014).

Ce qui est particulièrement intéressant à propos de cette mutation c'est qu'un nouvel allèle au locus MSTN a pu être créé de novo, par la méthode CRISPR-Cas9, directement dans le génome de moutons d'une race produisant une laine de haute qualité la Superfine Merino ${ }^{17}$ permettant ainsi d'additionner, en seulement deux générations, toutes les qualités zootechniques de la mutation "Callipyge" en ce qui concerne l'augmentation des masses musculaires, à celles de la race produisant une laine Superfine merino (de très haute qualité). Si cette stratégie n'avait

14- II existe, chez I'homme, une situation (naturelle) analogue à celle du SDRP : c'est le cas des mutations qui se rencontrent spontanément chez certains patients (CCR5- $\triangle 32$ ) et qui affectent le co-récepteur du virus VIH. Les patients homozygotes pour ce genre de mutations sont résistants au VIH. Cet épisode de l'histoire du VIH est connu sous I'appellation du "patient de Berlin": https://www.lemonde.fr/sante/article/2012/07/26/le-patient-de-berlin-seul-homme-a-avoir-gueri-dusida_1738151_1651302.html

15- Mais le prix à payer dans ce cas sera la création d'un nouveau réservoir de virus !

16- Les meilleurs morceaux de boucherie!

17- Une race élevée en Amérique du Sud, en Uruguay en particulier. 
pas été entreprise, on aurait pu parvenir au même résultat mais l'introgression de l'allèle muté du gène MSTN (et uniquement de cet allèle) dans le génome de moutons de la race Superfine merino aurait nécessité de nombreux croisements (Menchaca et al. 2018 ; Menchaca et al. 2020). D'autres exemples auraient pu être cités pour souligner le fait que, par les méthodes de mutagenèse ciblées (comme ZFN, TALEN ou CRISPR-Cas9), on peut faire apparaître, d'emblée un allèle nouveau d'une mutation connue dans pratiquement n'importe quel contexte génomique. On peut aussi remarquer qu'avec la méthodologie ZFN, TALEN ou CRISPR-Cas9, on peut créer en une seule étape, des individus pseudo-homozygotes (Hauschild et al. 2011) pour un allèle connu.

\section{Modifier le génome pour permettre la pratique d'éventuelles xénotransplantations}

Pour qu'une transplantation de cellules ou d'organe soit possible, il faut :

- que le greffon ait une probabilité élevée d'être accepté et, si possible, accepté définitivement par le receveur : c'est un problème d'histocompatibilité,

- qu'il ne fasse courir aucun risque au receveur (contamination par des virus oncogènes provenant du donneur via le greffon, par exemple). Ces deux conditions sont difficiles, voire impossibles, à satisfaire chez l'homme, c'est pourquoi les transplantations sont souvent difficiles à réaliser par manque de donneurs. L'idée d'utiliser les animaux domestiques (porc, mouton) comme donneurs d'organes potentiels (rein, cœur, foie...) était déjà venue à l'esprit des chirurgiens pour des raisons anatomiques physiologiques et pratiques mais le risque de contamination du receveur par des agents pathogènes provenant du donneur (notamment des virus) était une barrière difficile à franchir (Ritchie et al. 2008).

Il est désormais possible de modifier le génome du porc pour satisfaire (successivement et peut-être définitivement ?) à l'une puis à l'autre de ces deux conditions (Dolgin, 2021). Une équipe composée de chercheurs de plusieurs nationalités (Niu et al. 2017) est parvenue à débarrasser complètement et durablement le génome du porc des 62 copies de rétrovirus (porcine endogenous retrovirus - PERV) qu'il hébergeait. Une étape importante est donc franchie. Il reste désormais à modifier le génome des porcs donneurs potentiels en "éteignant", les uns après les autres, les gènes impliqués dans l'histocompatibilité - au moins les plus importants. Ce sera sans doute plus long que pour les rétrovirus car il faudra procéder à l'extinction de ces gènes l'un après l'autre mais ce ne sera pas nécessairement plus difficile. Des résultats encourageants ont déjà été publiées en la matière (Hauschild et al. 2011) et il n'est pas exclu que l'on puisse un jour disposer de porcs "humanisés" "donneurs universels". Seuls les préjugés, les empreintes culturelles et les problèmes éthiques resteront à contourner...?

\section{L'écornage génétique des bovidés et la castra- tion des porcelets ... sans douleurs !}

Les cornes sont un élément important du standard des races bovines et ovines. Certaines races ont des cornes - d'autres n'en ont pas, parfois naturellement parfois parce que le vétérinaire a été sollicité pour procéder à l'écornage chirurgical et ce point est parfois source de controverses ${ }^{18}$. Les cornes sont-elles importantes, nécessaires, dangereuses ? Faut-il écorner systématiquement les bovins pour qu'ils soient moins dangereux ? ou faut-il les laisser avec leurs cornes comme emblème du standard de la race ? Le problème n'est pas simple et comporte aussi un aspect éthique, notamment dans certains pays, car l'écornage est une intervention douloureuse, même pratiquée dans le jeune âge et sous anesthésie. Les généticiens sont en mesure de proposer une alternative à l'écornage "chirurgical" : l'écornage par knockout du gène POLLED. $\mathrm{Au}$ moins quatre mutations spontanées indépendantes ont été identifiées au locus POLLED (chromosome 1 des bovins). Ces mutations sont apparues dans les élevages et sont aujourd'hui connues en détail à l'échelon moléculaire. Prenant en compte les renseignements fournis par cette analyse structurale du locus, un nouvel allèle à ce locus a été produit récemment dans un laboratoire américain (Carlson et al. 2012) en utilisant les techniques TALEN et SCNT. D'autres allèles seront sans doute produits avec la même méthode ou avec la méthode CRISPR-Cas9, et les généticiens ont alors les moyens de créer de novo des spécimens sans corne, dans n'importe quelle race bovine, sans avoir à transférer la mutation naturelle par voie sexuée, ce qui est très long et par conséquent coûteux.

On ne peut pas clore cette liste d'exemples où l'édition de certaines régions du génome a été utilisée avec succès pour modifier, de manière radicale et au bénéfice de l'élevage, certaines caractéristiques zootechniques sans mentionner que des recherches sont actuellement en cours pour identifier de possibles "gènes-cibles" dont les mutations pourraient avoir des conséquences sur la différenciation des organes et des glandes sexuels et pourraient in fine éviter d'avoir à castrer les jeunes porcelets mâles à la puberté ${ }^{19}$ (Yunes et al. 2019). Le gène qui code le récepteur de la Kisspeptine (KISS1R), une hormone exprimée à la puberté par les cellules de la glande pituitaire, semblerait être un candidat de premier rang pour la mise en application de cette approche mais des résultats expérimentaux sont encore attendus. Cette compilation d'exemples récemment publiés montre clairement que les perspectives qui sont offertes par les différentes stratégies de réécriture du génome sont séduisantes à plus d'un titre. En effet, elles peuvent être génératrices de profit, elles peuvent être avantageuses pour la préservation de la santé de l'homme, elles peuvent améliorer le bien-être des animaux d'élevage etc. et pourtant elles sont à l'origine de controverses récurrentes et ne sont pas ou seulement très peu acceptées, notamment en Europe. Nous pensons que l'heure est venue de procéder à une sérieuse révision du cadre légal.

18- Le peuple suisse a été invité à se prononcer à ce sujet au travers d'une "votation" nationale.

19- Cette recherche est d'autant plus importante qu'il est envisagé, dans les prochaines années et dans le cadre de la préservation du bien-être animal, d'interdire (par la loi) la castration sanglante des 100 millions de porcelets qui naissent chaque année en Europe. 


\section{PLAIDOYER POUR UNE RÉVISION DE LA LÉGISLATION RELATIVE À L'ÉDITION GÉNÉTIQUE D'ANIMAUX DOMESTIQUES}

Lorsqu'on lance une recherche sur internet, par exemple pour se faire une opinion sur ce que sont les "Organismes Génétiquement Modifiés", on obtient une palette de réponses très variées. En tête, on trouve presque toujours la définition de "Greenpeace : "un organisme génétiquement modifié (OGM) est un organisme vivant dont l'ADN a été bricolé pour le doter de propriétés qu'il ne possédait pas naturellement". Plus en aval, dans la même liste, apparaît la définition de l'encyclopédie numérique "Wikipédia", qui déclare : "un organisme génétiquement modifié est un organisme vivant dont le génome a été modifié artificiellement. Cette définition inclut toutes les formes possibles de modifications de l'information génétique, allant de la méthode des croisements à l'ensemble des outils permettant de modifier la constitution génétique d'un organisme en supprimant, en introduisant ou en remplaçant de l'ADN."

En fait, ni l'une ni l'autre de ces définitions n'est pleinement satisfaisante. La première est méprisante et formulée de manière à inquiéter le lecteur, car les chercheurs qui produisent des OGM sont tout sauf des "bricoleurs"20. Produire des OGM requiert de l'imagination, une bonne connaissance de la biologie et un projet cohérent pour faire en sorte que l'expérience soit utile et/ou permette à la Science de progresser. La seconde définition est plus objective même si elle manque un peu de précision en ce sens qu'elle aurait dû mentionner que l'ADN éventuellement utilisé pour modifier la constitution génétique de l'organisme étudié pouvait, dans certains cas, provenir d'une autre espèce ou même être synthétisé de novo.

La confrontation de ces deux définitions conduit à des positions diamétralement opposées puisque, pour certains, le fait de modifier le génome in vitro est un acte contre-nature (c'est du bricolage), autrement dit un acte condamnable a priori, tandis que pour d'autres c'est un acte potentiellement générateur de diversité, donc intéressant et à encourager.

La lecture de ces deux définitions place d'emblée le lecteur au cour d'une controverse qui dure depuis un peu plus de vingt ans et qui pourrait à terme avoir des conséquences préjudiciables pour le monde agricole. La situation ne va sans doute pas se résorber d'elle-même dans un avenir prochain et les vétérinaires seront sans doute concernés, à plus d'un titre, par cette controverse : ils doivent donc s'y préparer. Pour installer cette réflexion nous formulons quelques commentaires et des suggestions portant sur quelques points précis.

\section{La législation relative aux OGM devrait être extensivement révisée}

Dans la communauté européenne, le statut des OGM est détaillé dans la Directive 2001/18/CE du 12 mars 2001 à laquelle est venu s'ajouter un arrêté de la cour européenne de justice en date du 25 juillet 2018.

Avant même d'avoir fait l'analyse détaillée de cette directive on trouvera sans doute surprenant qu'un même cadre légal puisse s'imposer à tous les OGM quel que soit le règne auquel ils appartiennent (règne animal, règne végétal ou microorganisme). La notion de "dissémination" par exemple, dont il est question à maintes reprises dans le texte de la directive, n'a pas du tout la même signification et n'impose pas les mêmes contraintes à l'agriculteur désireux de cultiver une variété de maïs transgénique et à son collègue éleveur, propriétaire d'un troupeau de moutons dont le génome a été génétiquement modifié in vitro. Dans le cas du maïs, la dissémination du pollen est très difficile voire impossible à maîtriser alors que le suivi du troupeau de moutons OGM, dont les animaux sont tous identifiables individuellement, ne pose aucun problème. On pourrait donc souhaiter, en premier lieu, que la législation afférente aux OGM soit revue et adaptée à des groupes plus homogènes et mieux définis d'êtres vivants. À ce titre, les animaux domestiques devraient constituer une catégorie à part puisque la quasi-totalité des individus d'une espèce donnée peuvent (ou pourraient être) identifiés à l'unité, très tôt après leur naissance, et le demeurer jusqu'à leur mort. Pour la plupart des animaux de rente et des animaux de compagnie il est très facile de suivre les filiations successives. Cela veut dire que si un animal domestique dont l'organisme aurait été génétiquement modifié devait un jour être reconnu comme étant à l'origine "d'effets négatifs sur la santé humaine, sur la santé animale ou sur l'environnement" (comme il est dit dans le texte de la directive), le "clone" auquel il appartient pourrait être immédiatement repéré, borné, puis tout entier éliminé et l'expérience arrêtée. Cette situation très avantageuse est particulière aux animaux domestiques et plaide pour une révision de la directive prenant cet avantage en compte. Un autre point à noter est que la directive 2001/18/CE est aujourd'hui vieille de vingt ans. Elle a été rédigée à une époque où les techniques de modification du génome étaient relativement imprécises ce qui pouvait entraîner un risque dû à des artéfacts difficilement contrôlables tels que la production de mutations "off-target"21 (hors-cibles) ou de mutations aux effets non-désirables. A l'heure actuelle ce risque est réduit et il est même devenu inexistant si certaines précautions sont prises au cours des étapes techniques d'édition du génome. Les endonucléases programmables, les outils les plus utilisés de nos jours, sont de plus en plus fiables et agissent avec un taux d'erreur négligeable (Shin et al. 2017, Lee et al. 2020). Les modifications ciblées du génome peuvent désormais se faire au nucléotide près, ce qui n'était pas possible il y a vingt ans et la stabilité de ces mêmes modifications peut aussi être suivie dans le temps par exemple par séquençage intégral du génome. En matière de réécriture du génome plus rien désormais n'est laissé au hasard! Enfin, la littérature spécialisée, qui commence à devenir abondante après 20 ans de pratique de la "transgénèse" dans le monde entier, n'a semble-t-il jamais rapporté d'effets négatifs (ou même inattendus) suite à la création d'un animal génétiquement modifié ! Dans une note intitulée "Point de vue d'Académiciens"22 certains membres de l'Académie d'Agriculture de France déclarent: "Pour aucun des OGM actuellement en service dans le monde, il n'existe à ce jour de raisons sérieuses d'affirmer l'existence d'un danger particulier, que ce soit pour la santé humaine ou

20- On imagine mal les organismes nationaux ou supra-nationaux financer des projets faisant appel au "bricolage" pour leur réalisation... !

21- Cette expression qualifie les éventuelles implantations d'un transgène dans une région non-ciblée et par définition inconnue.

22- Cette phrase est extraite d'un document annexé à l'avis officiel de l'Académie d'agriculture (Référence ci-joint). https://www.academie-agriculture.fr/publications/ publications-academie/points-de-vue/reecriture-du-genome-ethique-et-confiance-les 
l'environnement dans son ensemble. Il est certes impossible d'affirmer qu'aucun danger n'existera jamais (et cela justifie la prudence). Mais il serait absurde de prendre des précautions exagérées, sans rapport avec l'ampleur des risques potentiels, en regard des avantages qu'ils apportent".

En conclusion, on peut considérer que, de nos jours, tous les individus génétiquement modifiés provenant d'un élevage domestique sont identifiables, de leur naissance à leur mort, et qu'une éventuelle modification de la structure primaire du génome, qui aurait été réalisée par l'homme, serait contrôlable est traçable générations après générations. Peu d'espèces présentent autant de garanties. Cette remarque doit donc être, elle aussi, considérée comme une incitation à réviser la législation relative aux OGM pour l'assouplir et surtout pour la rendre plus adaptée au contexte actuel.

En France, les dossiers de qualification OGM sont instruits par l'Agence Nationale de Sécurité Sanitaire de l'Alimentation, de l'Environnement et du travail (ANSES) et par le Haut Conseil des Biotechnologies (HCB) et chaque OGM doit faire l'objet d'une demande d'autorisation particulière. Il serait donc logique et par conséquent souhaitable que les dossiers d'autorisation pour un OGM donné soient considérés au cas par cas et éventuellement révisés dans le temps.

La Directive 2001/18/CE du 12 mars 2001 spécifie que, pour être autorisés dans l'UE, les OGM ne doivent "pas avoir d'effets négatifs sur la santé humaine, sur la santé animale ou l'environnement" ; dans le doute, le principe de précaution doit s'appliquer. Malheureusement, comme chacun sait, il est difficile sinon impossible de déclarer "l'absence d'effets négatifs", dans ces conditions n'importe quel OGM risque de se retrouver placé "sous embargo" pour une durée indéfinie, donc illimitée. Ceci est excessif et injustifié et pourrait même être à l'origine d'un handicap lorsqu'un OGM particulier est susceptible de faire l'objet d'un échange ou d'une cession au niveau international.

\section{Certaines situations paradoxales plaident aussi pour une modification de la législation}

Comme déjà mentionné ci-dessus, plusieurs mutations au locus POLLED (sans cornes) sont apparues spontanément dans les élevages bovins au cours du temps et certaines sont aujourd'hui connues en détail à l'échelon moléculaire. Prenant en compte les enseignements fournis par ces analyses structurales, de nouveaux allèles au locus POLLED ont été produits par "gene editing" dans un laboratoire américain en utilisant les techniques TALEN et SCNT décrites ci-dessus (Tan et al. 2012 ; Carlson et al. 2012). Il existe donc désormais, dans le cheptel mondial, au moins deux types de bovins avec le même phénotype sans corne, parmi lesquels ceux qui dérivent d'un clone porteur d'une mutation naturelle, classique, comme par exemple les bovins de la race Aberdeen $A_{n g u s}{ }^{23}$, et ceux qui dérivent d'un taureau "virtuel" dont le génome aurait été modifié in vitro, par la technique SCNT (ou autre), par exemple dans le laboratoire du Dr Carlson (voir ci-dessus). En Europe, aux termes de la directive européenne, on ne peut élever et "disséminer" que la version "naturelle" et un éleveur qui souhaiterait posséder un troupeau d'une race précise (Aubrac par exemple) dans une version "sans cornes", n'aurait d'autre choix que de procéder lui-même à une série de croisements en retour classique pour "introgresser" par voie "mendélienne" le caractère "sans corne" d'origine naturelle dans la race choisie. Il s'agit certes d'une pratique éprouvée mais elle serait fort coûteuse et requerrait $5 / 10$ ans (Mueller et al 2019). Au contraire, s'il vivait en Uruguay, notre éleveur pourrait demander à un collègue généticien de créer, spécialement pour lui, et de novo, un allèle POLLED "sans corne" directement dans la race de son choix ce qui simplifierait et accélèrerait considérablement le processus (Clark \& Whitelaw, 2013 ; Menchaca et al 2018 ; Menchaca et al. 2020).

\section{L'édition de certains segments génomiques pourrait avoir des conséquences sanitaires et économiques avantageuses si elle était autorisée}

Dans cette revue, nous avons rapporté plusieurs exemples de modifications faites par l'homme, dans le génome des mammifères, qui se sont soldées par un bénéfice d'exploitation. C'est le cas des porcs rendus insensibles au virus du syndrome dysgénésique et respiratoire par la délétion d'un domaine de la protéine qui sert de récepteur au virus, c'est le cas des animaux homozygotes pour un allèle non fonctionnel de la myostatine et qui présentent un surdéveloppement de certaines masses musculaires (veaux, porcs et bovins culards), ce serait le cas des bovins génétiquement écornés et ce serait aussi le cas des bovins avec un allèle knockout de la protéine prion (travaux en cours), etc. Malheureusement, pour l'instant, ces modifications génomiques ne sont pas autorisées ... Nous pensons qu'il est temps de revenir sur ce sujet, comme le proposent certaines instances européennes (Bratlie et al. 2019) ou certains groupes de chercheurs, avec le soutien d'instances politiques (Le Déaut \& Procaccia, 2017a et 2017b). La situation actuelle de "moratoire" bloque la recherche sur de nombreux sujets et constitue un handicap pour les pays européens. Il semble urgent d'y mettre un terme car il n'est pas facile de trouver des financements pour des projets de recherche qui n'auraient pas de débouchés économiques clairement identifiés ${ }^{24}$.

Avant de conclure sur ce sujet nous devons souligner que la possibilité de modifier la sensibilité des animaux à certaines maladies infectieuses par édition d'un (ou de quelques) segment(s) de leur génome est probablement une aventure qui ne fait que commencer. Une meilleure connaissance, en termes de biologie moléculaire, des phases précoces de la rencontre entre les agents pathogènes et leurs hôtes ouvrira sans doute des voies de recherches nouvelles conduisant à d'autres médicaments ou à d'autres traitements plus efficaces, moins toxiques, moins chers...?

Les situations que nous avons relatées ci-dessus, avec le syndrome dysgénésique et respiratoire porcin (SDRP), les mammites à staphylocoques, la peste porcine, bientôt les

23- Voir le site australien "Online Mendelian Inheritance in Animals" http://omia.angis.org.au

24 - La Commission européenne s'est récemment engagée à faire évoluer les choses et un rapport est "en chantier" depuis avril 2021. 
encéphalopathies spongiformes (à prions) ne sont sans doute que des exemples précurseurs de situations plus générales et du plus haut intérêt à la fois pour les vétérinaires et les éleveurs. Allant dans ce sens, l'Académie vétérinaire de France a émis un avis sur le sujet le 21 juin 2019 qui résume la position de ses membres. Cet avis peut être consulté à https://academie-veterinaire-defrance. org/fileadmin/user_upload/Publication/PrisesPosition/ AVF_2019-06-21_AnimalGenetiquementModifie_Avis_V6.5finale.pdf

Cet avis doit être considéré comme un plaidoyer pour une révision de la législation actuellement en cours en Europe. À ce titre il est en parfait accord avec l'avis adopté par l'Académie d'Agriculture de France $^{25}$ et avec les recommandations de l'OPECST ${ }^{26}$.

\section{CONCLUSION}

Cet article, présenté sous la forme d'une revue avec de nombreux exemples, est destiné à mettre en évidence, une fois de plus, l'intérêt et la puissance des techniques modernes de modification (de réécriture) ciblée du génome (en anglais genome editing) et leur intérêt potentiel en matière d'élevage et de médecine vétérinaire. La mise en œuvre de ces techniques est relativement simple et ne nécessite pas d'équipement très sophistiqué, c'est pourquoi de nombreux projets sont en cours dans le monde entier (USA, Chine, Japon, Amérique du Sud, etc..). Par contre, les contraintes légales imposées par la Directive 2001/18/CE du 12 mars 2001, aux projets qui pourraient être entrepris dans la communauté européenne, sont fortes au point de placer l'Europe en situation d'attente ce qui a pour effet de ralentir ou même de paralyser les activités sans que la nécessité en soit clairement apparente. L'Académie Vétérinaire de France a émis un avis sur le sujet le 21 juin 2019 en appelant à un assouplissement et à une meilleure adaptation des règlements au contexte spécifiquement vétérinaire. L'Académie d'Agriculture a, à son tour, émis un avis en début de l'année 2020 dont les conclusions principales sont parfaitement en accord avec celles de l'Académie Vétérinaire. L'heure est venue de sortir de la situation de statu quo dans laquelle nous nous trouvons en procédant à une sérieuse révision des textes législatifs communautaires.

\section{CONFLITS D'INTÉRÊT}

L'auteur ne déclare aucun conflit d'intérêt dans la rédaction de cette revue qui n'exprime que son opinion personnelle.

\section{BIBLIOGRAPHIE}

- Bratlie S, Halvorsen K, Myskja BK, Mellegård H, Bjorvatn C, Frost P et al. A novel governance framework for GMO: A tiered, more flexible regulation for GMOs would help to stimulate innovation and public debate. EMBO Rep. 2019; 20(5): e47812.

- Burkard C, Lillico S, Reid E, Jackson, Ben Mileham A, Ait-Ali $\mathrm{T}$ et al. Precision engineering for PRRSV resistance in pigs: Macrophages from genome edited pigs lacking CD163 SRCR5 domain are fully resistant to both PRRSV genotypes while maintaining biological function. PLoS Pathog. 2017; 13(2): e1006206.

- Carbery ID, Ji D, Harrington A, Brown V, Weinstein EJ, Liaw L et al. Targeted genome modification in mice using zinc-finger nucleases. Genetics. 2010; 186: 451-459.

- Carlson DF, Tan W, Lillico SG, Stverakova D, Proudfoot C, Christian M et al. Efficient TALEN-mediated gene knockout in livestock. Proc Natl Acad Sci USA. 2012; 109(43): 17382-17387.

- Chesne P, Heyman Y, Peynot N, Renard JP. Nuclear transfer in cattle: birth of cloned calves and estimation of blastomere totipotency in morulae used as a source of nuclei. C R Acad Sci III. 1993;316(5):487-91. Erratum in: C R Acad Sci III 1993 Jul;316(7):641. PMID: 8053996.

- Clark AJ \& Whitelaw CBA. A future for transgenic livestock. Nat Rev Genet. 2013; 4: 825-833.

- Dolgin E. First GM pigs for allergies. Could xenotransplants be next? Nat Biotechnol 2021; 39, 397-400. https://doi.org/10.1038/s41587-021. 00885-9.

- Doudna JA \& Charpentier E. The new frontier of genome engineering with CRISPR-Cas9. Science 2014; 346: 1258096.

- Ducos A, Bed'hom B, Acloque H, Pain B. Modifications ciblées des génomes : apports et impacts potentiels des nouvelles technologies pour les espèces aviaires. Bull. Acad. Vét. France 2020 . DOI : 10.3406/bavf.2020.70900.

- Fässler R. Lentiviral transgene vectors. EMBO Rep. 2004; 5(1): 28-29.

- Gaj T, Gersbach CA, Barbas CF 3rd. ZFN, TALEN, and CRISPR/Cas-based methods for genome engineering. Trends Biotechnol. 2013; 31(7): 397-405.

- Geurts AM, Cost GJ, Freyvert Y, Zeitler B, Miller JC, Choi VM. Knockout rats via embryo microinjection of zinc-finger nucleases. Science 2009; 325: 433.

- Grobet L, Martin LJ, Poncelet D, Pirottin D, Brouwers B, Riquet J et al. A deletion in the bovine myostatin gene causes the double-muscled phenotype in cattle. Nat Genet. 1997; 17: 71-74.

- Guénet JL - Transgénèse et maîtrise des maladies infectieuses chez les animaux domestiques. Bull. Acad. Vét. France 2017; 170(1): 56-65.

- Hauschild J, Petersen B, Santiago Y, Queisser AL, Carnwath JW, Lucas-Hahn A et al. Efficient generation of a biallelic knockout in pigs using zinc-finger nucleases. Proc Natl Acad Sci 2011; 108: 12013-12017.

- Hofmann A, Kessler B, Ewerling S, Weppert M, Vogg B, Ludwig $\mathrm{H}$ et al. Efficient transgenesis in farm animals by lentiviral vectors. EMBO Rep. 2003; 4 :1054-1060.

- Houdebine LM. La transgénèse

25- Cet avis est accessible à l'adresse : https://www.academie-agriculture.fr/publications/publications-academie/avis/avis-reecriture-du-genome-ethique-et-confiance 26- Office parlementaire d'évaluation des choix scientifiques et technologiques. 
animale et ses applications. in : "Biotechnologies" Numéro spécial. INRA Prod. Anim. 1998 ; 11: 81-94.

- Houdebine LM. Production de protéines pharmaceutiques par des animaux transgéniques. Notes Académiques de l'Académie d'Agriculture de France (N3AF) $2016 ; 11: 1-16$.

- Houdebine LM. Les nouveaux outils des biotechnologies animales - Chapitre 3 in "Au-delà des OGM" - Science Innovation Société 2018 : pp67-91.

- Kalds P, Zhou S, Cai B, Liu J, Wang Y, Petersen B et al. Sheep and Goat Genome Engineering: From Random Transgenesis to the CRISPR Era. Front Genet. 2019; 10: 750. doi: 10.3389/fgene.2019.00750. PMID.

- Kim H \& Kim JS. A guide to genome engineering with programmable nucleases. Nat Rev Genet. 2014; 15 : 321-334.

- Le Déaut JY \& Procaccia C (2017) Les enjeux économiques, environnementaux, sanitaire et éthiques des biotechnologies à la lumière des nouvelles pistes de recherche. Rapportn ${ }^{\circ} 4618$ Assemblée nationale et $n^{\circ} 507$ Sénat tome 1, OPECST, 366 pages.

- Le Déaut JY \& Procaccia C. Une réflexion parlementaire pour l'avenir. in "Au-delà des OGM - Science-Innovation-Société" Académie d'Agriculture de France - Presse des Mines 2017. Chapitre 8 pp 181-196.

- Lee K, Uh K, Farrell K. Current progress of genome editing in livestock. Theriogenology 2020; 150: 229-235.

- Lillico SG, Proudfoot C, Carlson DF, Stverakova, Neil C, Blain C et al. Live pigs produced from genome edited zygotes Sci. Rep. 2013; 3: 2847, doi: 10.1038/srep02847.

- Lillico SG, Proudfoot C, King TJ, Tan W, Zhang L, Mardjuki R et al. Mammalian interspecies substitution of immune modulatory alleles by genome editing. Sci Rep. 2016; 6: 21645. doi: 10.1038/srep21645.

- Liu X, Wang Y, Tian Y, Yu Y, Gao M, $\mathrm{Hu} G$ et al. Generation of mastitis resistance in cows by targeting human lysozyme gene to $\beta$-casein locus using zinc-finger nucleases. Proc Biol Sci. 2014; 281(1780): 20133368. doi: 10.1098/rspb.

- Lois C, Hong EJ, Pease S, Brown EJ, Baltimore D. Germline transmission and tissue-specific expression of transgenes delivered by lentiviral vectors. Science 2002; 295 : 868-872.

- Ma T, Tao J, Yang M, He C, Tian X, Zhang $\mathrm{X}$ et al. An AANAT/ASMT transgenic animal model constructed with CRISPR/Cas9 system serving as the mammary gland bioreactor to produce melatonin-enriched milk in sheep. J Pineal Res. 2017 63(1). doi: 10.1111/jpi.12406.

- Mashimo T, Kaneko T, Sakuma T, Kobayashi J, Kunihiro Y, Voigt B et al. Efficient gene targeting by TAL effector nucleases co-injected with exonucleases in zygotes. Sci Rep 2013; 3: https://doi.org/10.1038/srep01253.

- Menchaca A, Dos Santos-Neto PC, Cuadro F, Souza Neves M, Crispo M. From reproductive technologies to genome editing in small ruminants an embryos journey. Animal Reprod. 2018; 15: 984-995.

- Menchaca A, dos Santos-Neto PC, Mulet AP, Crispo M. CRISPR in livestock: From editing to printing. Theriogenology 2020; 150: 247-254.

- Mueller ML, Cole JB, Sonstegard TS, Van Eenennaam AL. Comparison of gene editing versus conventional breeding to introgress the POLLED allele into the US dairy cattle population. J Dairy Sci. 2019; 102: 4215-4226.

- Niu D, Wei HJ, Lin L, George H, Wang $\mathrm{T}$, Lee $\mathrm{IH}$ et al. Inactivation of porcine endogenous retrovirus in pigs using CRISPR-Cas9. Science 2017; 357(6357):1303-1307.

- Palmiter RD, Brinster RL Hammer, RE, Trumbauer ME, Rosenfeld MG, Birnberg NC et al. Dramatic growth of mice that develop from eggs microinjected with metallothionein -growth hormone fusion gene. Nature 1982; 300 (5893) : 611-615.

- Regnault-Roger C, Houdebine LM, Ricroch A. Au-delà des OGM. Science-Innovation-Société. Académie d'Agriculture de France. 2017, Presses des Mines.

- Ritchie WA, King T, Neil C, Carlisle AJ, Lillico S, McLachlan G, Whitelaw CBA (2008) Transgenic sheep designed for transplantation studies. Mol Reprod Dev 76: 61-64.

- Salvesen $\varnothing$, Espenes A, Reiten MR, Vuong TT, Malachin G, Linh T, et al. Goats naturally devoid of $\mathrm{PrPC}$ are resistant to scrapie. Vet Res 2020; 51: 1-14.

- Schibler L. L'édition génomique des bovins : une opportunité, mais pas à n'importe quel prix. Bull. Acad. Vet France 2020; DOI : $10.3406 /$ bavf.2020.70901.

- Shin J, Jiang F, Liu JJ, Bray NL, Rauch BJ, Baik SH et al. Disabling Cas9 by an anti-CRISPR DNA mimic. Sci Adv. 2017; 12; 3(7): e1701620.

- Tait-Burkard C, Doeschl-Wilson A, McGrew MJ, Archibald AL, Sang, HM, Houston et al. Livestock 2.0 genome editing for fitter, healthier, and more productive farmed animals Genome Biology 2018;19: 204.

- Tan WS, Carlson, DF, Walton MW, Fahrenkrug SC Hackett PB. Precision editing of large animal genomes. Advances in Genetics 2012; 80: 37-97.

Van Eenennaam AL. Application of genome editing in farm animals: cattle.

- Transgenic Res. 2019 Aug;28(Suppl 2): 93-100. doi: $10.1007 / \mathrm{s} 11248-019-0$ 0141-6. PMID: 31321690.

- Wang J, Yang P, Tang B, Sun X, Zhang R, Guo C et al. Expression and characterization of bioactive recombinant human alpha-lactalbumin in the milk of transgenic cloned cows. J Dairy Sci. 2008; Dec;91(12):4466-76.

- Whitelaw C, Joshi A, Kumar S, Lillico S, Proudfoot C. Genetically engineering milk. Journal of Dairy Research; 2016, 83(1), 3-11.

- Wilmut I, Schnieke A, McWhir J. Kind AJ, Campbell KH. Viable offspring derived from fetal and adult mammalian cells. Nature 1997; 385: 810-813. https://doi.org/10.1038/385810a0.

- Yunes MC, Teixeira DL, von Keyserlingk MAG, Hötzel MJ. Is gene editing an acceptable alternative to castration in pigs? PLoS ONE 2019; 14(6): e0218176.

- Zhang C, Wang L, Ren G, Li Z, Ren C, Zhang $\mathrm{T}$, et al. Targeted disruption of the sheep MSTN gene by engineered zinc-finger nucleases. Mol Biol Rep. 2014; 41(1): 209-15.

- Zhou W, Wan Y, Guo R, Deng M, Deng K, Wang Z et al. Generation of beta-lactoglobulin knock-out goats using CRISPR/Cas9. PLoS One 12(10) 2017; e0186056. https://doi. org/10.1371/journal.pone.0186056 